The UBC State Social Connection Scale: Factor Structure, Reliability, and Validity

Iris Lok and Elizabeth Dunn

University of British Columbia

Correspondence concerning this article should be addressed to Iris Lok, Department of

Psychology, University of British Columbia, Vancouver, British Columbia, V6T 1 Z4.

Email: iris.lok@psych.ubc.ca

Word count: 4285 


\begin{abstract}
Social connection plays a central role in people's everyday lives. Although researchers have traditionally focused on the benefits of experiencing an enduring sense of social connection, recent research has also begun to explore the contextual factors that shape momentary feeling of social connection. To date, however, no psychological scales have been developed to measure social connection at the state level. To address this gap, we developed and validated the 10-item UBC State Social Connection Scale. In Study 1, we generated and refined our initial pool of items and confirmed our hypothesized factor structure in a large university sample. In Studies 2 and 3, we established several forms of validity and demonstrated that state social connection is related to but distinct from trait social connection. Taken together, we provide foundational evidence that the UBC State Social Connection Scale is a reliable and valid instrument for assessing momentary feelings of social connection.
\end{abstract}

Keywords: Social Connection, Belonging, Well-Being, Scale, Measure 


\section{The UBC State Social Connection Scale: Factor Structure, Reliability, and Validity}

Humans have a fundamental need for belonging. More than 25 years ago, Baumeister and Leary (1995) argued that people are innately motivated to form strong and positive social relationships, and achieve a sense of belonging that is characterized by a feeling of being socially connected to others. Since then, a large body of literature has examined the benefits of experiencing a stable and long-term sense of belonging (for a review, see Baumeister \& Leary, 1995). In more recent years, researchers have shifted their attention to understanding the contextual factors that shape people's ability to satisfy their belongingness needs. For example, Reis and colleagues (2000) found that people felt more socially connected when they engaged in social activities, such as talking about something meaningful and hanging out with others. Building on this work, Sandstrom and Dunn (2014) demonstrated that simply exchanging a brief conversation with a Starbucks cashier can lead to a greater sense of belonging. However, this sense of social connection that people derive from social interactions can be significantly undermined by the use of smartphones (e.g., Kushlev \& Dunn, 2019). Across all of these studies, researchers have tried to capture momentary feelings of social connection by creating their own ad-hoc measures or adapting trait measures of social connection. However, researchers are increasingly recognizing that utilizing unvalidated measures with unknown psychometric properties can severely undermine their ability to make valid and reliable inferences about human behavior (e.g., Flake, Pek, \& Hehman, 2017). Thus, the goal of the current research was to develop a valid and reliable instrument for measuring state social connection.

To date, researchers have developed various measures to capture trait levels of social connection. For example, the Social Connection Scale Revised (SCS-R; Lee, Draper, \& Lee, 2001) includes 20 items that measure people's feelings of closeness to the social world; it includes items that ask about specific social relationships (e.g., "My friends feel like family"), 
as well as items that tap into a more general sense of social connection (e.g., "I am in tune with the world."). In a similar vein, the General Belongingness Scale (GBS; Malone, Pillow, \& Osman, 2012) uses 12 items to assess the extent to which people have achieved a sense of belonging. Like the SCS-R, the scale contains a wide range of items that capture experiences of social connection in specific contexts (e.g., "I have close bonds with family and friends") as well as more global contexts (e.g., "I feel connected with others."). To capture the opposite of social connection, researchers have also measured loneliness using the 20 -item UCLA Loneliness Scale (Russell, 1993), which measures how often people experience a sense of social isolation, using items such as, "How often do you feel that you lack companionship?" and "How often do you feel that there is no one you can turn to?"

In contrast, there are no existing scales that measure momentary feelings of social connection. As a result, researchers must adapt items from trait measures of social connection (e.g., SCS-R and GBS) or develop their own items for measuring state social connection. Although it is not uncommon for state and trait measures to be used interchangeably, researchers have argued that state and trait measures are meant to capture theoretically distinct constructs. Zuckerman (1983), for example, outlined all of the key features that differentiate trait and state scales. In particular, he argued that state- but not trait—measures should be sensitive to momentary changes in a given situation. Thus, a person's state level of social connection should change following a brief social interaction, whereas their trait levels of social connection should remain relatively stable over time. In addition, researchers are increasingly recognizing the importance of validating survey instruments - even if they are simply adapting or re-purposing an existing scale (Flake and Fried, 2020). Because modifying the instructions and items on a scale can change its psychometric properties, adapted measures need to be re-evaluated to ensure that they are reliable and valid. As Furr (2011) puts it, "a modified scale is — to some degree — an ad hoc scale." 
In the current research, we developed a measure of state social connection. To create our scale while maximizing consistency with past work, we adapted items from existing measures of trait social connection including the SCS-R and GBS. We then assessed the structure of the UBC State Social Connection Scale using exploratory and confirmatory factor analysis (Study 1) and evaluated the extent to which the scale demonstrated several forms of validity (Studies 2 and 3). The materials, data, and code for all of our studies are available at https://tinyurl.com/9kr6j9b6.

\section{Study 1}

The goal of Study 1 was to develop and refine a measure of state social connection. We created an initial pool of 11 items that were adapted from existing measures of trait social connection including the SCS-R (Lee, Draper, \& Lee, 2001) and the GBS (Malone, Pillow, \& Osman, 2012; see Table 1 for list of items). We selected items using two rules: (1) the items should capture a general feeling of connection that is not specific to any situation, individual, or group, (2) the items should capture a wide range of subjective experiences, in that some of the items would be endorsed more often ("easy" items), while some of the other items would be endorsed less often ("difficult" items). Then, we created a set of instructions that went along with our pool of items. Because the scale is meant to capture momentary feelings of social connection, our instructions first ask participants to think about how they felt during a particular window of time (e.g., in the last 15 minutes, in the last 24 hours). Then, participants are asked to indicate to what extent each of the eleven items describe how they felt. Finally, we collected data from a large sample of participants and conducted a series of exploratory and confirmatory factor analyses to assess the factor structure of our scale. 


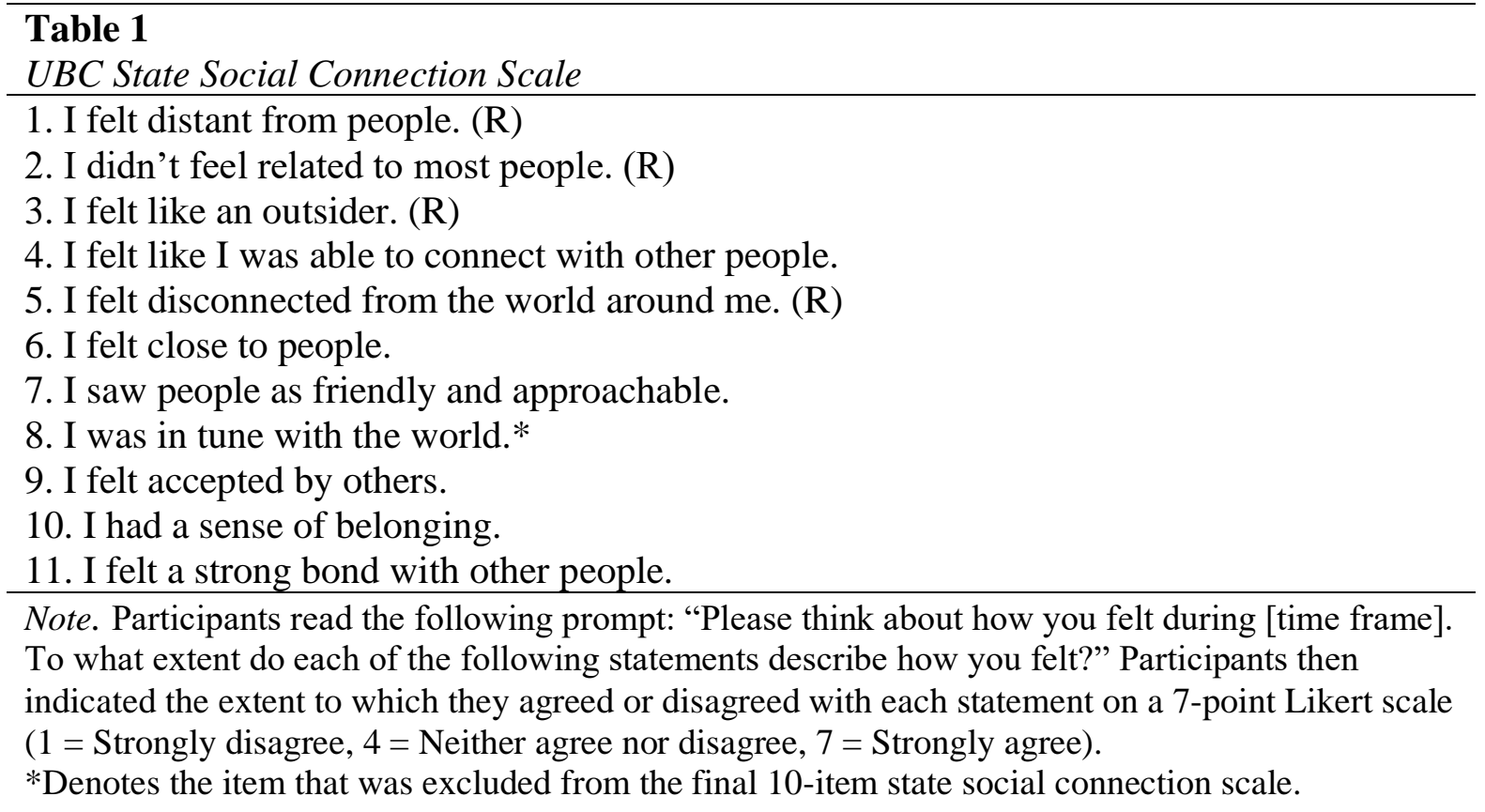

\section{Method}

\section{Participants and Procedures}

We planned to collect as much data as possible from a department-wide pretesting survey. Based on past experience with this recruitment strategy, we expected our sample to consist of at least 1000 participants. In total, 1031 undergraduate students enrolled in a large Canadian university $\left(M_{a g e}=21.2, S D_{a g e}=3.7 ; 45.4 \%\right.$ East Asian, $21.1 \%$ European, $11.4 \%$ South Asian, 9.5\% South East Asian, 6.6\% Other, 3.4\% Middle Eastern, 1.3\% African, 1.3\% Hispanic, 0.1\% First Nations; 76.3\% Female, 2.3.1\% Male, 0.5\% Other, 0.1\% Trans) completed the UBC State Social Connection Scale in exchange for course credit.

To measure state social connection, we presented participants with the following instructions: "Please think about how you felt today. To what extent do each of the following statements describe how you felt?" Then, we asked participants to indicate the extent to which they agreed or disagreed with each item on a scale from 1 (Strongly Disagree) to 7 (Strongly Agree). 


\section{Results}

We split our sample into two halves and conducted exploratory factor analysis (EFA) on one half $(N=515)$, and confirmatory factor analysis (CFA) on the other half $(N=516)$. This approach allowed us to test whether our hypothesized factor structure is sustained in each independent sample.

\section{Exploratory Factor Analysis}

Factor Extraction. We used scree plots and parallel analysis to determine the appropriate number of factors to extract from our model. The scree plot pointed to a onefactor solution, whereas parallel analysis pointed to the possibility of a two-factor solution. Thus, we conducted EFAs to test a one- and two-factor solution.

One-Factor Solution. We tested a one-factor solution using least squares extraction with the psych package in R. The standardized factor loadings ranged from .64 to .81 (see Table 2); in other words, the latent factor explained at least $41 \%$ of the observed variance for each item. Overall, the one-factor solution accounted for $53 \%$ of the observed variance across the 11 items. We also examined the correlation between the item residuals (see Table 3). On average, the reverse-coded items were associated with larger residuals, suggesting that participants may be responding to those items differently.

Table 2

One-Factor EFA Solution

\begin{tabular}{lcc}
\hline Item & $\begin{array}{c}\text { Standardized } \\
\text { Loading }\end{array}$ & Mean (SD) \\
\hline 1. I felt distant from people. (R) & .72 & $4.08(1.64)$ \\
2. I didn't feel related to most people. (R) & .71 & $4.52(1.49)$ \\
3. I felt like an outsider. (R) & .72 & $4.62(1.62)$ \\
4. I felt like I was able to connect with other people. & .77 & $4.87(1.37)$ \\
5. I felt disconnected from the world around me. (R) & .67 & $4.21(1.62)$ \\
6. I felt close to people. & .81 & $4.77(1.48)$ \\
7. I saw people as friendly and approachable. & .70 & $4.95(1.33)$ \\
8. I was in tune with the world. & .64 & $4.47(1.34)$ \\
9. I felt accepted by others. & .75 & $5.10(1.29)$ \\
10. I had a sense of belonging. & .78 & $4.83(1.43)$ \\
11. I felt a strong bond with other people. & .76 & $4.85(1.45)$ \\
\hline
\end{tabular}


Table 3

One-Factor EFA Solution Residual Correlation Matrix

\begin{tabular}{|c|c|c|c|c|c|c|c|c|c|c|c|}
\hline Item & 1 & 2 & 3 & 4 & 5 & 6 & 7 & 8 & 9 & 10 & 11 \\
\hline 1. I felt distant from people. (R) & - & .13 & .08 & -.07 & .40 & -.03 & -.12 & -.04 & -.18 & -.16 & -.12 \\
\hline 2. I didn't feel related to most people. (R) & & - & .32 & -.11 & -.001 & -.07 & -.05 & -.10 & -.12 & -.06 & -.05 \\
\hline 3. I felt like an outsider. (R) & & & - & -.17 & .01 & -.17 & -.03 & -.07 & .08 & .03 & -.17 \\
\hline 4. I felt like I was able to connect with other people. & & & & - & -.03 & .09 & .10 & .01 & .02 & .02 & .17 \\
\hline 5. I felt disconnected from the world around me. (R) & & & & & - & -.14 & -.14 & .27 & -.18 & -.14 & -.23 \\
\hline 6. I felt close to people. & & & & & & - & .02 & -.02 & .01 & .07 & .24 \\
\hline 7. I saw people as friendly and approachable. & & & & & & & - & .02 & .15 & .04 & .04 \\
\hline 8. I was in tune with the world. & & & & & & & & - & -.04 & .01 & -.06 \\
\hline 9. I felt accepted by others. & & & & & & & & & - & .17 & .05 \\
\hline 10. I had a sense of belonging. & & & & & & & & & & - & .06 \\
\hline 11. I felt a strong bond with other people. & & & & & & & & & & & - \\
\hline Mean Residual Correlation (in absolute value) & .13 & .10 & .11 & .08 & .15 & .09 & .07 & .06 & .10 & .08 & .12 \\
\hline
\end{tabular}


Two-Factor Solution. We tested a two-factor solution using least squares extraction and oblimin rotation using the psych package in $\mathrm{R}$. Table 4 presents the results of our analysis. The first factor tapped into social connection; the six items that loaded strongly onto this factor were all positively worded statements that referred to feeling a strong sense of connection (e.g., "I felt like I was able to connect with other people"). The second factor tapped into social disconnection; the four items that strongly loaded onto this factor were all negatively worded statements that referred to a lack of connection (e.g., "I felt distant from people"). Of course, because these four items were all reverse-coded, the second factor might also reflect common-method variance (e.g., participants responding to reverse-coded items in a systematic way). In any case, there was a strong positive correlation between the two factors $(r=.74)$. Thus, it may be more appropriate to reduce the two factors into a single factor. The two-factor solution also revealed a problematic item that did not strongly load onto either factor ("I was in tune with the world."). This suggests that the item might not be measuring social connection in the way that we intended. Indeed, the problematic item was the only item that did not make any reference to other people or the feeling of being connected.

\section{Table 4}

Two-Factor EFA Solution

\begin{tabular}{lccc} 
& \multicolumn{2}{c}{ Loadings } & Mean (SD) \\
\cline { 2 - 3 } Item & Factor 1 & Factor 2 & \\
\hline I felt distant from people. (R) & .03 & $\mathbf{. 7 7}$ & $4.00(1.63)$ \\
I didn't feel related to most people. (R) & .28 & $\mathbf{4 8}$ & $4.43(1.57)$ \\
I felt like an outsider. (R) & .31 & $\mathbf{. 4 5}$ & $4.57(1.64)$ \\
I felt like I was able to connect with other people. & $\mathbf{. 7 2}$ & .08 & $4.83(1.44)$ \\
I felt disconnected from the world around me. (R) & -.07 & $\mathbf{. 8 3}$ & $4.21(1.63)$ \\
I felt close to people. & $\mathbf{. 7 8}$ & .07 & $4.71(1.47)$ \\
I saw people as friendly and approachable. & $\mathbf{. 7 1}$ & .02 & $4.97(1.28)$ \\
I was in tune with the world. ${ }^{\mathrm{a}}$ & .30 & .38 & $4.37(1.37)$ \\
I felt accepted by others. & $\mathbf{. 8 2}$ & -.04 & $5.07(1.28)$ \\
I had a sense of belonging. & $\mathbf{. 7 7}$ & .05 & $4.94(1.42)$ \\
I felt a strong bond with other people. & $\mathbf{. 8 7}$ & -.08 & $4.70(1.53)$ \\
\hline
\end{tabular}

Note. Standardized factor loadings $>.40$ are bolded.

${ }^{a}$ Indicates items with weak loadings on each factor. 
Based on our results, we retained a one-factor solution with all items loading onto a single factor representing state social connection. To account for common method variance, we cross-loaded the four reverse-coded items onto a second factor representing method effects. Finally, we removed the problematic item ("I was in tune with the world") from our scale. Figure 1 illustrates our final hypothesized factor model.

\section{Confirmatory Factor Analysis}

We tested our final hypothesized factor model using the lavaan package in R. We accounted for any missing data using maximum likelihood estimation. To assess model fit, we assessed the following fit indices: chi-square test of exact fit, Comparative Fit Index (CFI), Tucker-Lewis Index (TLI), root mean square error of approximation (RMSEA), and squared root mean residual (SRMR).

\section{Figure 1}

Final Hypothesized Factor Model

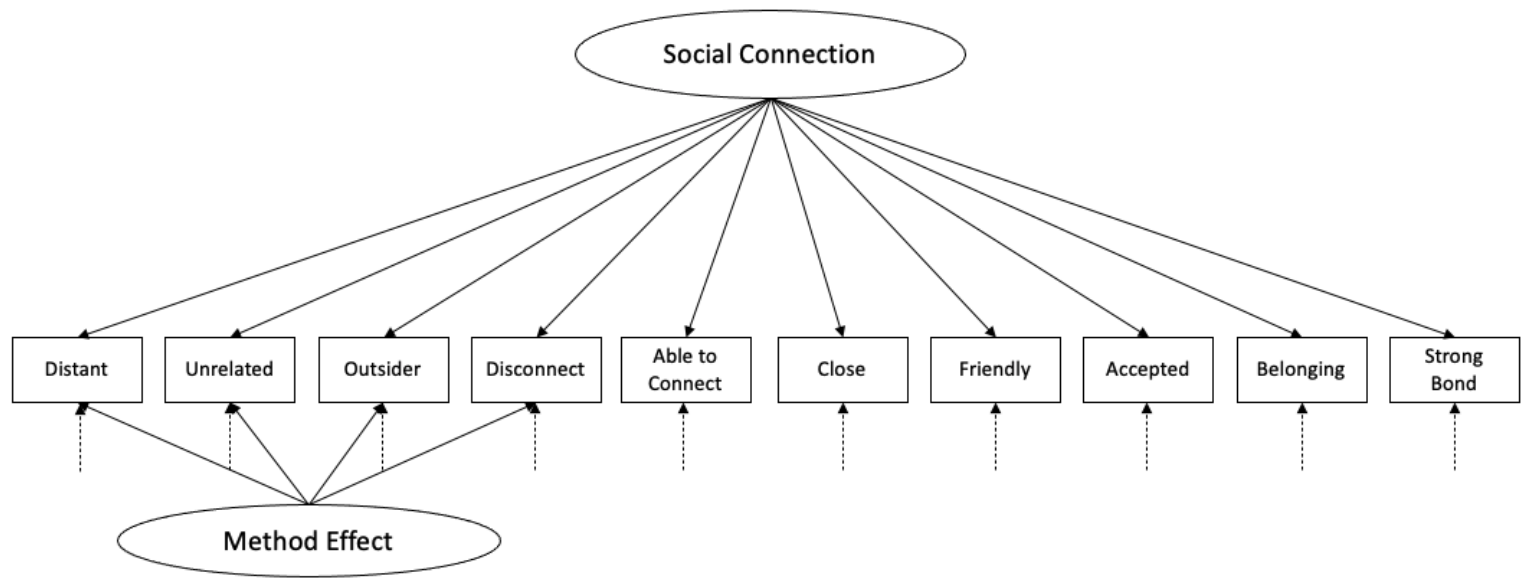

Table 5 presents the results of our analysis. Overall, the model fit the data well based on the CFI (0.97), TLI (0.96), RMSEA (0.08), and SRMR (0.02), although it did not satisfy the $\chi^{2}$ test of exact fit (which is expected in large samples; see Bandalos, 2018). In addition, we did not find any large residual correlations between any of the items (all $r$ 's $<|.07|$ ). The social connection factor also demonstrated high levels of reliability $(\alpha=.92 ; \omega=.93)$. 


\begin{tabular}{lcc}
\hline $\begin{array}{l}\text { Table 5 } \\
\text { Final Hypothesize Factor Model CFA Solution }\end{array}$ & & \\
\hline & \multicolumn{2}{c}{ Standardized Factor Loading } \\
\cline { 2 - 3 } Item & $\begin{array}{c}\text { Social } \\
\text { Connection }\end{array}$ & $\begin{array}{c}\text { Method } \\
\text { Effect }\end{array}$ \\
\hline 1. I felt distant from people. (R) & .64 & .53 \\
2. I didn't feel related to most people. (R) & .68 & .36 \\
3. I felt like an outsider. (R) & .68 & .33 \\
4. I felt like I was able to connect with other people. & .79 & - \\
5. I felt disconnected from the world around me. (R) & .56 & .46 \\
6. I felt close to people. & .85 & - \\
7. I saw people as friendly and approachable. & .60 & - \\
8. I felt accepted by others. & .80 & - \\
9. I had a sense of belonging. & .83 & - \\
10. I felt a strong bond with other people. & .81 & - \\
\hline
\end{tabular}

\section{Discussion}

In Study 1, we confirmed our hypothesized factor structure using a large sample of participants. Each item loaded strongly onto the latent factor representing state social connection (with the underlying construct explaining at least $\approx 30 \%$ of the observed variance for each item). In addition, our items did not seem to suffer from ceiling or floor effects based on their means and standard deviations — which tended to fall towards the middle of the scale (see Table 2 and 4). In Study 2 and 3, we sought to establish the validity of the UBC State Social Connection Scale.

\section{Study 2}

Study 2 was motivated by three goals. The first goal was to test whether the UBC State Social Connection Scale exhibits known-groups validity: Is the scale able to discriminate between groups that should differ in their momentary levels of social connection? To address this question, we randomly assigned participants to write about the last experience in which they spent time either alone or with others. Because social connection is characterized by feeling accepted, feeling close to others, as well as a sense of belonging, we expected participants to report higher levels of social connection when they spent time with other people (vs. alone). 
The second goal was to assess construct validity more broadly by looking at the relationship between the UBC State Social Connection Scale and other theoretically-relevant constructs including mood, satisfaction with life, and loneliness. Because social connection is associated with both affective and cognitive dimensions of subjective well-being (see Diener \& Seligman, 2002), we expected state social connection to be associated with higher levels of positive mood and life satisfaction and lower levels of negative mood and loneliness.

Finally, the third goal was to test whether state and trait social connection are related but distinct constructs by looking at the correlation between trait and state levels of social connection. We also compared the correlation between state-state, trait-trait, and state-trait measures. Based on Zuckerman's (1983) criteria for distinguishing state and trait measures, we expected state measures of positive and negative mood to be more strongly associated with state-rather than trait—levels of social connection. In contrast, we expected trait measures of life satisfaction, loneliness, and extraversion to be more strongly associated with trait—rather than state-levels of social connection.

\section{Methods}

\section{Overview}

We measured participants' trait levels of social connection, satisfaction with life, loneliness, and extraversion. Then, we randomly assigned them to think about a time when they were either alone or with others, and asked them to report their state levels of social connection and mood in that situation.

\section{Participants and Procedures}

Because we expected to observe a relatively large difference between conditions, as well as strong correlations between our measures, we recruited 202 participants from Prolific (65.84\% Male, 33.17\% Female, 0.99\% Non-Binary/Others; $80.20 \%$ White, $7.43 \%$ Other, 6.44\% Asian, 4.46\% Mixed, 1.49\% Black; $\left.M_{\text {age }}=29.01, S D_{a g e}=8.88\right)$ who completed the 
study in exchange for 1.50 Canadian dollars. Based on a sensitivity analysis conducted in $\mathrm{G}^{*}$ Power 3.1, this sample size enabled us to detect a medium-to-large effect size $(d=0.40)$ and small correlation $(r=.19)$ with $80 \%$ Power (two-tailed).

Upon providing consent, participants completed all of our trait measures:

Trait Social Connection. To measure trait social connection, we presented participants with 20 statements reflecting the various ways in which people can view themselves (e.g., "I fit in well in new situations") using the SCS-R (Lee, Draper, \& Lee, $2001 ; \alpha=.95)$. We then asked them to rate the extent to which they agree or disagree with each statement on a scale from 1 (Strongly disagree) to 6 (Strongly agree).

Life Satisfaction. To measure life satisfaction, we asked participants to rate their satisfaction with life using the 5-item Satisfaction with Life Scale (Diener et al., 1985; $\alpha=$ 90). Participants rated their agreement with statements like, "In most ways, my life is close to my ideal" and "I am satisfied with my life" on a scale from 1 (Strongly disagree) to 7 (Strongly agree).

Loneliness. To measure loneliness, we asked participants to report how often they feel lonely using the 20-item UCLA Loneliness Scale Version 3 (Russell, 1996; $\alpha=.94$ ). Participants responded to statements like, "How often do you feel alone?" and "How often do you feel that your relationships with others are not meaningful?" on a scale from 1 (Never) to 4 (Always).

Extraversion. To measure extraversion, we asked participants to rate the extent to which a number of characteristics (e.g., "Is outgoing, sociable") apply to them on a scale from 1 (Disagree strongly) to 5 (Agree strongly), using the six-item extraversion subscale from the BFI-2-S (Soto \& John, 2017; $\alpha=.79$ ).

Then, participants were randomly assigned to one of two conditions. In the alone condition, participants were told to describe the most recent occasion in which they spent 
time alone. In the together condition, participants were told to describe the most recent occasion in which they spent time with people they cared about. Afterwards, participants reported their state level of social connection and mood during the experience they had just described. Finally, they reported their age, gender, and ethnicity.

State Social Connection. To measure state social connection, we asked participants to think about how they felt during the experience they had just described, and to report the extent to which they agreed with our 10 items on a scale from 1 (Strongly disagree) to 7 (Strongly agree; $\alpha=0.95)$.

Mood. To measure mood, we asked participants to indicate how often they felt a range of positive emotions (e.g., "Good") and negative emotions (e.g., "Sad") during the experience they described on a scale from 1 (Very rarely or never) to 5 (Very often or always) using 12 items from the Scale of Positive and Negative Experiences (Diener et al., 2009; $\alpha$ Positive Affect $\left.=.95, \alpha_{\text {Negative Affect }}=.93\right)$.

\section{Results}

To assess known-groups validity, we compared participants' ratings of state social connection in the alone versus together condition. As expected, participants in the together condition reported feeling more socially connected while thinking about their experience $(M$ $=5.35, S D=1.24)$ compared to those in the alone condition $(M=3.54, S D=1.29), t(199.95)$ $=-10.14, p<.001, d=1.42$.

Next, we assessed a broader form of construct validity by looking at the zero-order correlations for state social connection, trait social connection, positive and negative mood, life satisfaction, loneliness, and extraversion (see Table 6). Across both conditions, feeling socially connected at the state level was strongly associated with higher levels of positive mood and life satisfaction, and lower levels of negative mood and loneliness. 
We also found a moderate positive correlation between trait and state levels of social connection $(r=.54)$. Consistent with Zuckerman's (1983) theorizing, state measures of positive and negative mood were more strongly correlated with state social connection than with trait social connection. Likewise, trait measures of life satisfaction, loneliness, and extraversion were more strongly correlated with trait social connection than with state social connection. Together, these findings provide preliminary evidence that state and trait social connection are related but distinct constructs (for significance tests, see Table 7).

\section{Table 6}

Correlation Across Variables in Study $2(\mathrm{~N}=202)$

\begin{tabular}{lccccccc}
\hline & 1 & 2 & 3 & 4 & 5 & 6 & 7 \\
\hline 1. State Social Connection & - & $.54^{*}$ & $.69^{*}$ & $-.60^{*}$ & $.30^{*}$ & $-.52^{*}$ & $.29^{*}$ \\
2. Trait Social Connection & & - & $.39^{*}$ & $-.35^{*}$ & $.52^{*}$ & $-.87^{*}$ & $.62^{*}$ \\
3. State Positive Mood & & & - & $-.78^{*}$ & $.37^{*}$ & $-.43^{*}$ & $.23^{*}$ \\
4. State Negative Mood & & & & - & $-.27^{*}$ & $.40^{*}$ & -.12 \\
5. Trait Life Satisfaction & & & & & - & $-.57^{*}$ & $.40^{*}$ \\
6. Trait Loneliness & & & & & & - & $-.56^{*}$ \\
7. Trait Extraversion & & & & & & & - \\
\hline Mean & 4.44 & 3.58 & 3.48 & 2.11 & 3.76 & 2.49 & 2.69 \\
SD & 1.56 & 0.92 & 1.05 & 1.05 & 1.39 & 0.57 & 0.79 \\
\hline
\end{tabular}

$* p<.001$

\section{Table 7}

Difference Between Paired Correlations

\begin{tabular}{lcccc}
\hline & \multicolumn{2}{c}{ Correlation $(r)$} & & \\
\cline { 2 - 3 } Measure & $\begin{array}{c}\text { State Social } \\
\text { Connection }\end{array}$ & $\begin{array}{c}\text { Trait Social } \\
\text { Connection }\end{array}$ & & $p$ \\
\hline State Positive Affect & .69 & .39 & 6.04 & $<.001$ \\
State Negative Affect & -.60 & -.35 & -4.50 & $<.001$ \\
Trait Life Satisfaction & .30 & .52 & -3.68 & $<.001$ \\
Trait Loneliness & -.52 & -.87 & 9.99 & $<.001$ \\
Trait Extraversion & .29 & .62 & -6.03 & $<.001$ \\
\hline
\end{tabular}

\section{Discussion}

In Study 2, we found some preliminary evidence of construct validity. First, we showed that participants who wrote about spending time with others (vs. by themselves) reported higher levels of state social connection while thinking about that experience 
(establishing known-groups validity). Second, we demonstrated that state social connection was associated with higher levels of positive mood and life satisfaction, and lower levels of negative mood and loneliness (establishing construct validity). Finally, participants reported state levels of social connection that were moderately correlated with their trait levels of social connection, which were reported at the beginning of the study; this provides some initial evidence that trait and state social connection are related but distinct constructs. In Study 3, we built on this initial work by examining whether the UBC State Social Connection Scale can capture something meaningful about people's social realities.

\section{Study 3}

In Study 3, our primary goal was to further validate the UBC State Social Connection Scale. By definition, state social connection measures an individual's subjective evaluation about how socially connected they feel to others in a particular moment in time. Developing and validating an instrument that taps into people's internal thoughts and feelings comes with its own unique set of challenges. In particular, Lucas (2018) notes that, "unlike certain selfreport measures (such as those for height, weight, grade point average, or even for some ratings of physical health), there is no gold standard against which self-report measures of subjective well-being can be compared" (p. 3). To mitigate this problem, Study 3 examined whether pairs of strangers who exchanged a brief conversation reported similar levels of social connection when they were asked to reflect on their experience. If the UBC State Social Connection Scale is capturing something meaningful about people's social reality, then pairs who share the same social experience should provide ratings that are at least somewhat correlated with each other. At the same time, we did not expect an extremely high correlation because people may perceive the same experience in different ways. 


\section{Methods}

\section{Participants and Procedures}

Participants were 122 undergraduate students $(\mathrm{N}=66$ pairs $)$ enrolled in a large Canadian university $\left(\mathrm{M}_{\mathrm{age}}=20.22, \mathrm{SD}_{\mathrm{age}}=2.06 ; 85.25 \%\right.$ Female; $48.36 \%$ Asian, $18.03 \%$ Caucasian, $11.48 \%$ Southeast Asian, 9.84\% South Asian, 6.56\% Other/Mixed, $4.10 \%$ Middle Eastern, 1.64\% Hispanic/Latino). All participants received course credit in exchange for their time and participation. The data were collected as a part of a larger study and the sample size was determined based on the goals of that study. Based on a sensitivity analysis conducted in G*Power 3.1, our sample size enabled us to detect a small-to moderate correlation $(r=.34)$ with $80 \%$ Power (two-tailed).

Upon arriving at the laboratory, participants were greeted by a research assistant and brought into separate rooms to be briefed about the study. After providing consent, participants were told that they would be engaging in an unstructured conversation with another student ${ }^{1}$. Then, participants were brought into the same room and spent the next fifteen minutes interacting with each other. After the conversation ended, participants returned to their individual rooms and completed the UBC State Social Connection Scale $(\alpha=$ .89). Specifically, they rated how socially connected they felt during the last fifteen minutes of the study. They also completed several other measures as a part of a larger study.

\section{Results}

To assess whether pairs of participants reported similar levels of social connection, we correlated state social connection ratings within pairs. There was a significant positive correlation $(r=.29, t(59)=2.35, p=.02)$, although the relationship was not very large presumably because people experience the same social situation differently. These results

\footnotetext{
${ }^{1}$ Half of the pairs completed questions about what they expected from the upcoming conversation as a part of a larger study. The questions were unrelated to the current research and thus not described in this paper.
} 
support the conclusion that state social connection ratings are tied to people's social reality. If state social connection was unrelated to people's social experience, ratings provided by pairs of strangers would be unlikely to be correlated with each other.

\section{General Discussion}

Across three studies, we developed and validated the UBC State Social Connection Scale. In Study 1, we created our initial pool of items by adapting from existing measures of trait social connection. This approach facilitated comparisons of state and trait measures of social connection in later studies. Then, we refined our items and confirmed our hypothesized factor structure in a large sample of undergraduate students. In Study 2, we established that the scale was psychometrically sound - correlating with theoretically-relevant constructs and discriminating between how socially connected participants felt when they were alone versus with other people. Furthermore, we presented some initial evidence that state and trait social connection were related but distinct constructs. In Study 3, we showed that the scale captured a meaningful part of social reality. In particular, we found a positive correlation in ratings of state social connection between pairs of strangers who exchanged a brief conversation with each other. Together, these findings suggest that the UBC State Social Connection Scale is a reliable and valid measure of state social connection.

An important limitation of the current research is that the scale may not be suitable for all cultures. Although the scale was shown to be reliable and valid among undergraduate students in Canada (Study 1 and 3) and adults in the US and UK (Study 2), it is unclear whether the scale would demonstrate similar psychometric properties in populations outside Europe and North America. Thus, it would be worthwhile to test the scale in other cultural contexts.

Across many disciplines from psychology to public health, researchers are increasingly recognizing the importance of social connection in people's lives. Indeed, a lack 
of social connection has been associated with a myriad of negative outcomes (for a review, see Holt-Lunstad, Robles, \& Sbarra, 2017). In one meta-analysis, for example, researchers claimed that a lack of social connection was just as lethal as smoking 15 cigarettes a day (Holt-Lunstad, Smith, \& Layton, 2010). Thus, to combat what is increasingly called the "loneliness epidemic," an important first step will be to identify the contextual factors that promote a sense of social connection. For example, social psychologists might draw from past research and test whether introducing a "no technology" policy in the first few minutes before class will help students feel more socially connected with their peers. The UBC State Social Connection Scale contributes to this endeavor by offering a valid and reliable instrument for evaluating whether interventions — such as a "no technology" policy—can lead to meaningful changes in people's momentary feelings of social connection. 


\section{References}

Bandalos, D. L. (2018). Measurement theory and applications for the social sciences. Guilford Publications.

Baumeister, R. F., \& Leary, M. R. (1995). The need to belong: Desire for interpersonal attachments as a fundamental human motivation. Psychological Bulletin, 117(3), 497529. https://doi.org/10.1037/0033-2909.117.3.497

Diener, E., Emmons, R. A., Larsen, R. J., \& Griffin, S. (1985). The Satisfaction With Life Scale. Journal of Personality Assessment, 49(1), 71-

75. https://doi.org/10.1207/s15327752jpa4901_13

Diener, E., Lucas, R., Schimmack, U., \& Helliwell, J. F. (2009). Well-being for public policy. Oxford University Press.

Diener, E., \& Seligman, M. E. P. (2002). Very happy people. Psychological Science, 13(1), 81-84. https://doi.org/10.1111/1467-9280.00415

Diener, E., Wirtz, D., Tov, W., Kim-Prieto, C., Choi, D.-w., Oishi, S., \& Biswas-Diener, R. (2010). New well-being measures: Short scales to assess flourishing and positive and negative feelings. Social Indicators Research, 97(2), 143156. https://doi.org/10.1007/s11205-009-9493-y

Dwyer, R. J., Kushlev, K., \& Dunn, E. W. (2018). Smartphone use undermines enjoyment of face-to-face social interactions. Journal of Experimental Social Psychology, 78, 233239. https://doi.org/10.1016/j.jesp.2017.10.007

Flake, J. K., \& Fried, E. I. (2020). Measurement schmeasurement: Questionable measurement practices and how to avoid them. Advances in Methods and Practices in Psychological Science, 3(4), 456-465. https://doi.org/10.1177/2515245920952393 
Flake, J. K., Pek, J., \& Hehman, E. (2017). Construct validation in social and personality research: Current practice and recommendations. Social Psychological and Personality Science, 8(4), 370-378. https://doi.org/10.1177/1948550617693063

Furr, M. (2011). Scale construction and psychometrics for social and personality psychology. SAGE Publications Ltd.

Holt-Lunstad, J., Robles, T. F., \& Sbarra, D. A. (2017). Advancing social connection as a public health priority in the United States. American Psychologist, 72(6), 517530. https://doi.org/10.1037/amp0000103

Holt-Lunstad, J., Smith, T. B., \& Layton, J. B. (2010). Social relationships and mortality risk: A meta-analytic review. PLoS Medicine, 7(7), e1000316e1000316. https://doi.org/10.1371/journal.pmed.1000316

Kahneman, D., Krueger, A. B., Schkade, D. A., Schwarz, N., \& Stone, A. A. (2004). A survey method for characterizing daily life experience: The day reconstruction method. Science, 306(5702), 1776-1780. https://doi.org/10.1126/science.1103572

Kushlev, K., \& Dunn, E. W. (2019). Smartphones distract parents from cultivating feelings of connection when spending time with their children. Journal of Social and Personal Relationships, 36(6), 1619-1639. https://doi.org/10.1177/0265407518769387

Lee, R. M., Draper, M., \& Lee, S. (2001). Social connectedness, dysfunctional interpersonal behaviors, and psychological distress: Testing a mediator model. Journal of Counseling Psychology, 48(3), 310-318. https://doi.org/10.1037/0022-0167.48.3.310

Lucas, R. E. (2018). Reevaluating the strengths and weaknesses of self-report measures of subjective well-being. In E. Diener, S. Oishi, \& L. Tay (Eds.), Handbook of WellBeing. Salt Lake City, UT: DEF. Publishers. 
Malone, G. P., Pillow, D. R., \& Osman, A. (2012). The General Belongingness Scale (GBS): Assessing achieved belongingness. Personality and Individual Differences, 52(3), 311-316. https://doi.org/10.1016/j.paid.2011.10.027

Reis, H. T., Sheldon, K. M., Gable, S. L., Roscoe, J., \& Ryan, R. M. (2000). Daily wellbeing: The role of autonomy, competence, and relatedness. Personality and Social Psychology Bulletin, 26(4), 419-435. https://doi.org/10.1177/0146167200266002

Russell, D. W. (1996). UCLA loneliness scale (version 3): Reliability, validity, and factor structure. Journal of Personality Assessment, 66(1), 20-

40. https://doi.org/10.1207/s15327752jpa6601_2

Soto, C. J., \& John, O. P. (2017). Short and extra-short forms of the Big Five Inventory-2: The BFI-2-S and BFI-2-XS. Journal of Research in Personality, 68, 6981. https://doi.org/10.1016/j.jrp.2017.02.004

Zuckerman, M. (1983). The distinction between trait and state scales is not arbitrary: Comment on Allen and Potkay's "On the arbitrary distinction between traits and states." Journal of Personality and Social Psychology, 44(5), 10831086. https://doi.org/10.1037/0022-3514.44.5.1083 